$3 \quad$ Field-Effect Transistor Based on an in Situ Grown Metal-

$4 \quad$ Organic Framework Film as a Liquid-Gated Sensing Device

${ }^{1}$ Key Lab of Materials Physics, Anhui Key Lab of Nanomaterials and Nanotechnology,

$7 \quad$ Institute of Solid State Physics, Chinese Academy of Sciences, Hefei 230031, China

$8 \quad{ }^{2}$ University of Science and Technology of China, Hefei, 230026, China

$9{ }^{3}$ Wuhan National Laboratory for Optoelectronics, School of Optical and Electronic

10 Information, Huazhong University of Science and Technology, Wuhan 430074, China

$11{ }^{*}$ Correspondence: duangt@,hust.edu.cn 
Scooping-up method: $0.3 \mathrm{~mL}$ of $\mathrm{NH}_{3} \cdot \mathrm{H}_{2} \mathrm{O}$ was added into the solution of

$2 \mathrm{NiCl}_{2} \cdot 6 \mathrm{H}_{2} \mathrm{O}(6.6 \mathrm{mg}, 0.019 \mathrm{mmol})$ with the deionized (DI) water of $5 \mathrm{~mL}$ in a $25 \mathrm{~mL}$

3 beaker. Afterwards, the mixture was dropped into the solution of HATP $6 \mathrm{HCl}(10.0 \mathrm{mg}$,

$40.028 \mathrm{mmol}$ ) in the $5 \mathrm{~mL}$ of DI water, put in a water bath and open heated to $65{ }^{\circ} \mathrm{C}$

5 reacting for $15 \mathrm{~min}$. A cleaned $\mathrm{Au}$-patterned $\mathrm{Si} / \mathrm{SiO}_{2}$ wafer was used to transfer the film

6 after cooling down to room temperature and the device was dried in a vacuum oven at

$7 \quad 100{ }^{\circ} \mathrm{C}$ for $2 \mathrm{~h}$. It was tough to obtain the intact MOF film through the scooping-up

8 method and the morphology of MOF film with cracks was shown in the Figure S5a,

9 that was also the main reason why the electrical properties of FETs made in this way were not very good (Figure S5b-c).

Drop-casting method: The experimental steps are similar to the above scoopingup method and the reaction time was controlled to be $120 \mathrm{~min}$. The reacted product was centrifuged three times with the DI water and ethanol, respectively and dried in a vacuum oven at $100{ }^{\circ} \mathrm{C}$ for $12 \mathrm{~h}$. Finally, an appropriate amount of dried Ni-MOF powders was mixed with the ethanol, and then dropped on the channel of the FET and baked in a vacuum oven at $100{ }^{\circ} \mathrm{C}$ for $2 \mathrm{~h}$. In this way, the nanosheets of Ni-MOF were stacked into a mass (Figure S5d) lacking of the film advantages of uniformity and continuity, which had an adverse effect on the electrical properties of the FETs (Figure S5e-f).

Characterization. The surficial morphologies and cross-sectional thicknesses of $\mathrm{Ni}-\mathrm{MOF}$ in situ grown on the $\mathrm{Si} / \mathrm{SiO}_{2}$ substrate were observed by the Scan electron microscope (SEM) and the Transmission electron microscope (TEM). Afterward the 
structural investigations were measured with Powder X-ray Diffraction (PXRD), X-ray photoelectron spectroscopy (XPS) and Thermogravimetric analysis (TGA, at a heating rate of $10{ }^{\circ} \mathrm{C} \cdot \mathrm{min}^{-1}$ under air atmosphere).

Electrical measurement. The electrical properties of Ni-MOF-FET were characterized through a Keithley 4200 semiconductor parameter analyzer combined with a four-probe probe station at room temperature under the dry and solution condition, respectively. The $\mathrm{Ids}_{\mathrm{ds}}-\mathrm{V}_{\mathrm{ds}}$ curves were used to evaluated the transfer characteristics meanwhile the $\mathrm{Ids}_{\mathrm{ds}}-\mathrm{V}_{\mathrm{gs}}$ curves were obtained to determine the transfer characteristics. The Si layer of Ni-MOF-FET was utilized as the gate terminal when measured under dry condition. And a silver wire was inserted into the well with PBS solution of $5 \mu \mathrm{L}$ and served as the gate electron of Ni-MOF-FET which was used as a liquid-gated FET. Gluconic acid solution of different concentrations $\left(10^{-6} \mathrm{~g} / \mathrm{mL}-10^{-3}\right.$ $\mathrm{g} / \mathrm{mL}$ ) was made with PBS, of which $5 \mu \mathrm{L}$ was added into the solution well for testing after rinsing for three times with the analyte of the same concentration.

Calculation: The threshold voltage $\left(V_{t h}\right)$ acquired from $I_{d s}{ }^{1 / 2}-V_{g s}$, and the carrier mobility $(\mu)$ was given in the linear region by the equation ${ }^{1}$ :

$$
I_{d s}=\frac{W}{L} \mu C_{i} V_{d s}\left(V_{g s}-V_{t h}\right)
$$

Where the $I_{d s}$ and $V_{g s}$ were the drain-source current and gate voltage extracted from the $I_{d s}-V_{g s}$ plots, respectively, $C_{i}$ was the capacitance of dielectric layer, which was approximately at the value of $11 \mathrm{nF} / \mathrm{cm}^{2}$ for $\mathrm{SiO}_{2}$ with $300 \mathrm{~nm}, \mathrm{~W}$ and $\mathrm{L}$ were the width and length of channels of FET, respectively.

The subthreshold swing (SS) was defined as ${ }^{2}$ : 
2 Therefore, the values of SS were from the reciprocal of the slope of the linear region of $3 \quad I_{d s}-V_{g s}$ plots.

4

\section{Additional Figures}

(a)
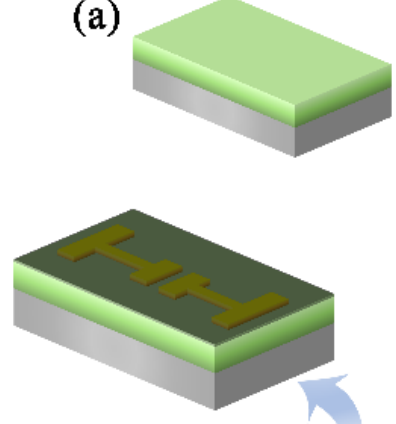

(g)
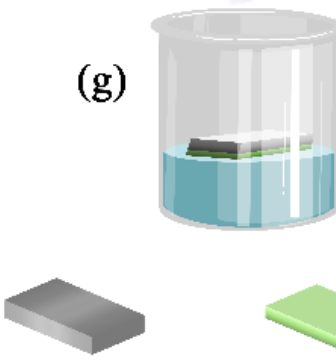

Si layer (b)

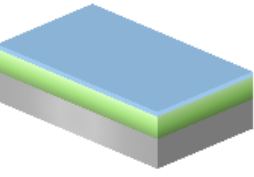

(f)
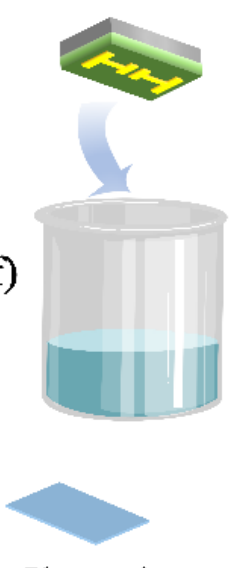

(c)

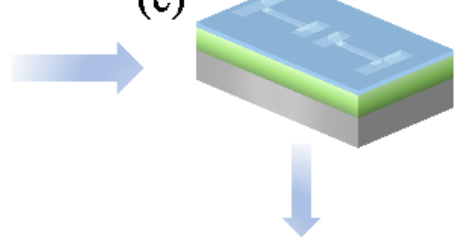

(d)

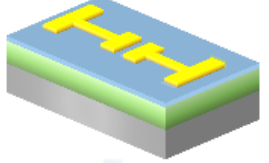

(e)
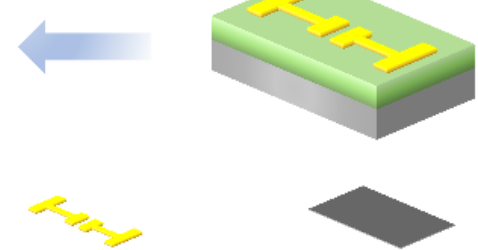

Au electrodes

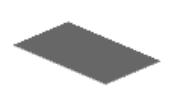

NiMOF membrane

Figure S1. Schematic illustration of the preparation progress of Ni-MOF-FET: $(a, b, c$, and ( $f, g)$ the in situ growth of the Ni-MOF on the FETs. 
4

5

6

7

8
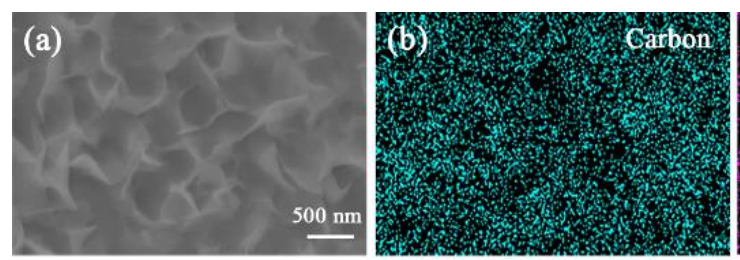
(d) nitrogen. (a)
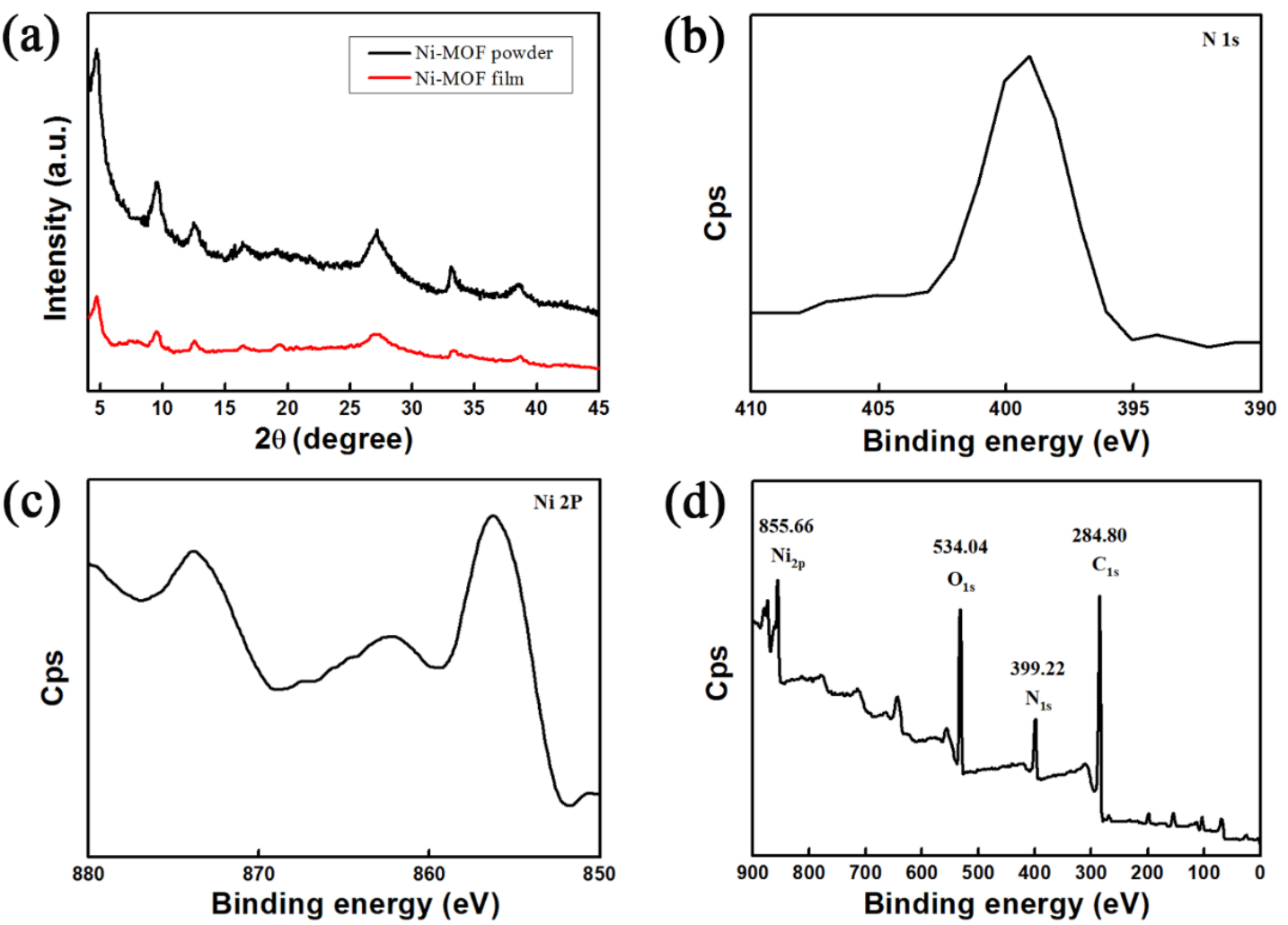

Figure S2. (a) PXRD pattern of the Ni-MOF powders and films. (b) XPS spectra of the Ni-MOF film. XPS spectra of high-resolution of (c) the Ni $2 p$ and (d) the N1s.
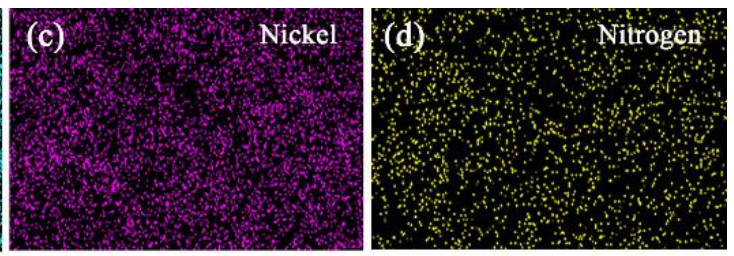

Figure S3. (a) HRSEM of the Ni-MOF film. Element mapping of (b) carbon, (c) nickel, 

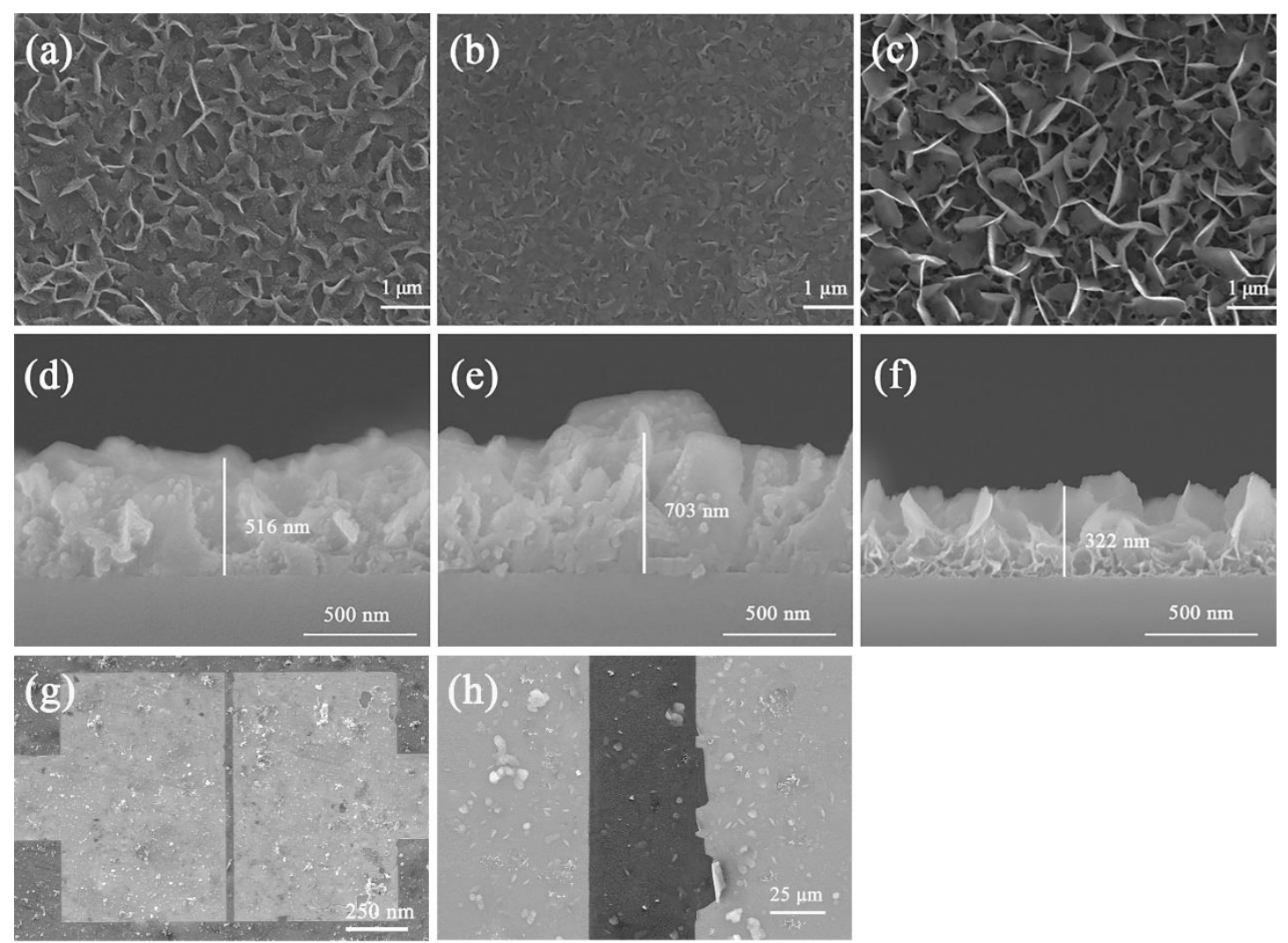

2 Figure S4. SEM images and cross-section images of the Ni-MOF with reacting for (a,

3 d) 60 min with Au electrodes, (b, e) 120 min with Au electrodes, (c, f) 60 min without

4 Au. SEM images of (g) the Ni-MOF-FET and (h) the morphology of the Ni-MOF in

5 channels reacting for $120 \mathrm{~min}$.

6 
(a)

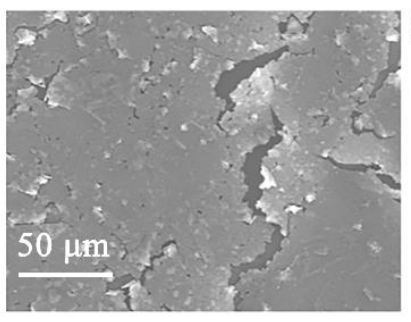

(d)

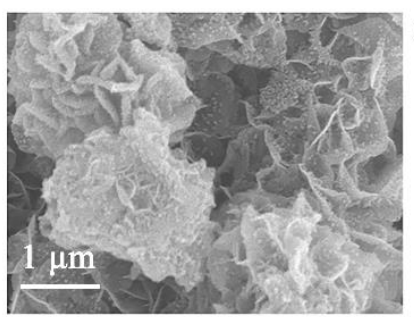

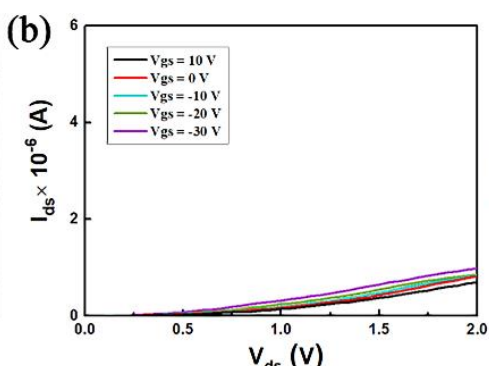

(e)

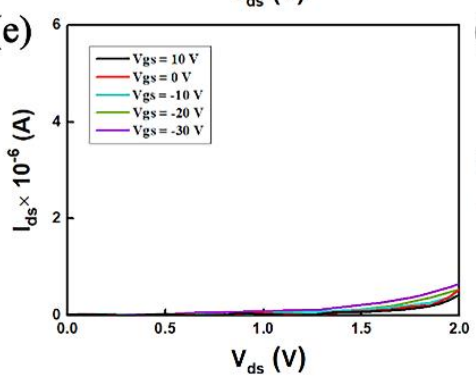

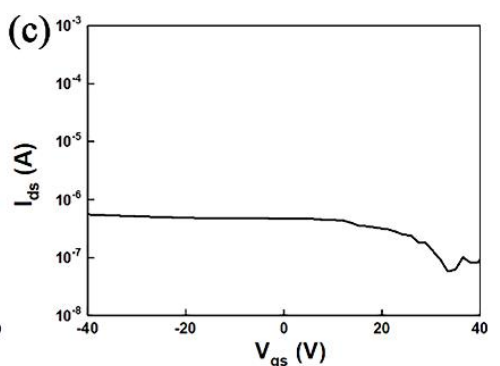

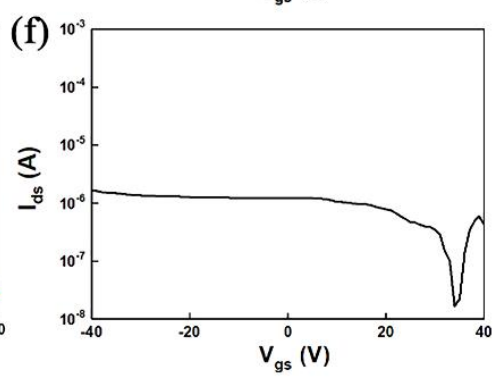

5

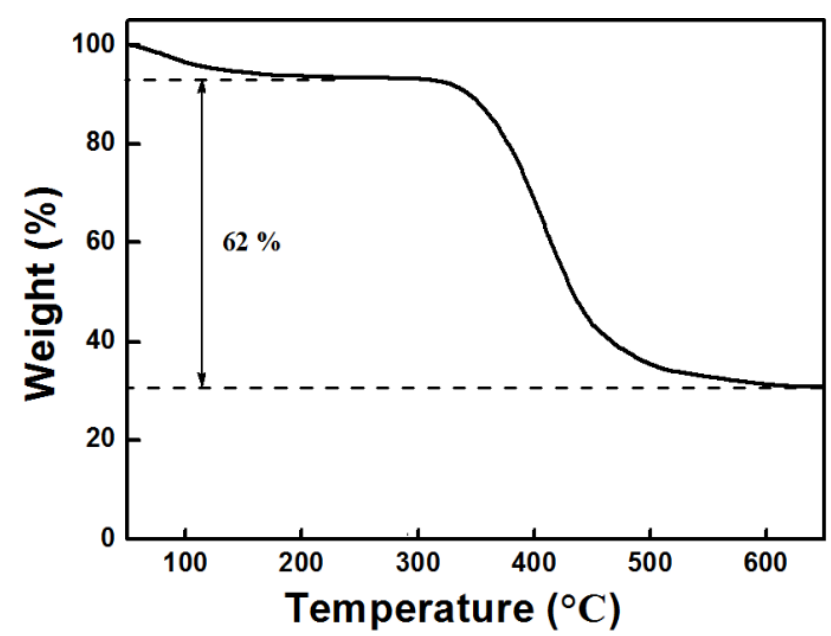

Figure S6. TG curve of the Ni-MOF powders in air at a ramp of $10^{\circ} \mathrm{C} / \mathrm{min}$. 
(a)

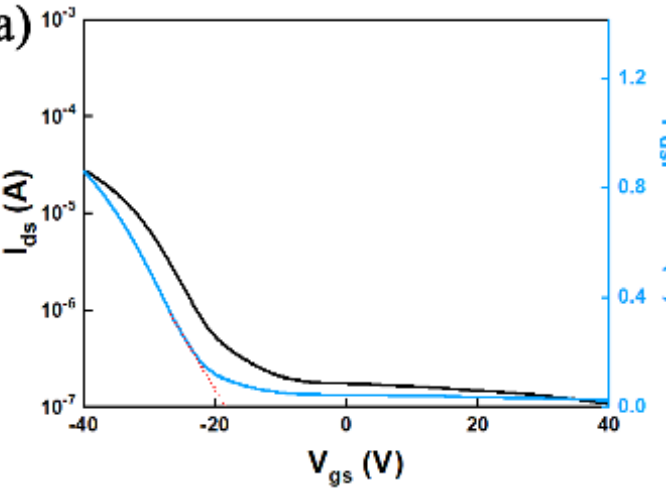

(c)

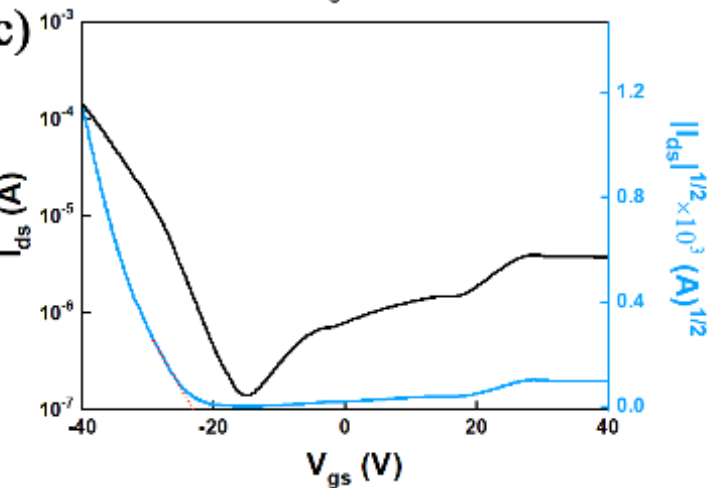

(b)

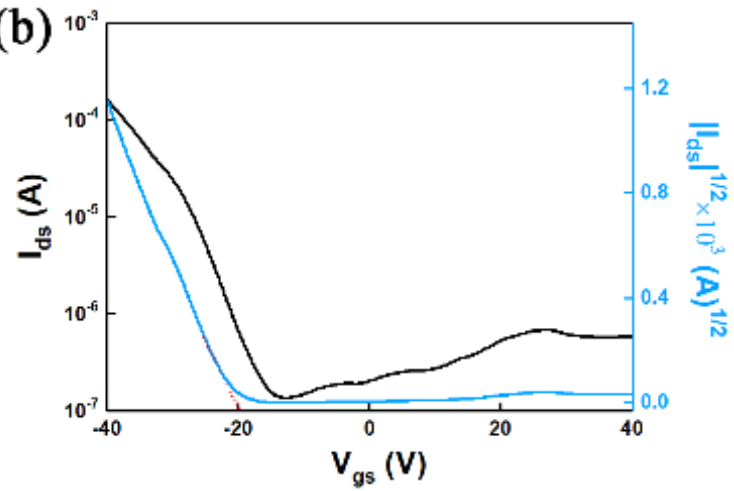

(d)

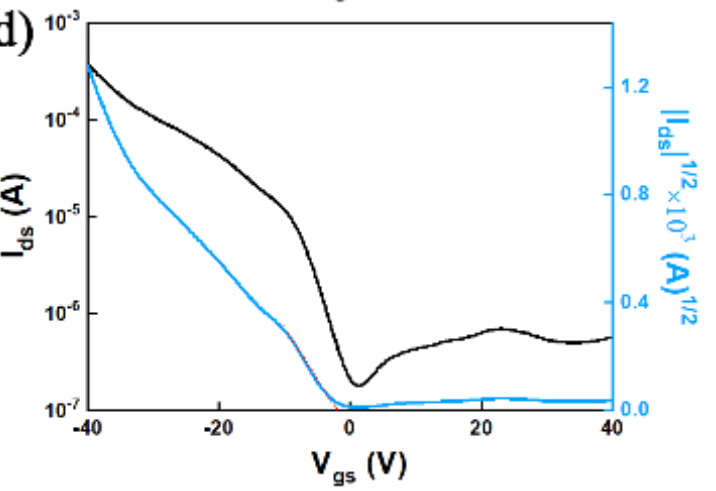

2 Figure S7. Left: actual current $\left(\mathrm{I}_{\mathrm{ds}}\right)$ versus gate voltage $\left(\mathrm{V}_{\mathrm{gs}}\right)$, right: square root of current $\left(\mathrm{Ids}^{1 / 2}\right)$ versus gate voltage $\left(\mathrm{V}_{\mathrm{gs}}\right)$. The threshold voltages and subthreshold swings were (a) $-19 \mathrm{~V}$ and $2.7 \mathrm{~V} /$ decade $(5 \mathrm{~min})$, (b) $-23 \mathrm{~V}$ and $2.3 \mathrm{~V} /$ decade $(15 \mathrm{~min})$, (c) $-19 \mathrm{~V}$ and $2.0 \mathrm{~V} /$ decade $(30 \mathrm{~min})$, (d) $-2 \mathrm{~V}$ and $1.3 \mathrm{~V} /$ decade $(60 \mathrm{~min})$, respectively. 


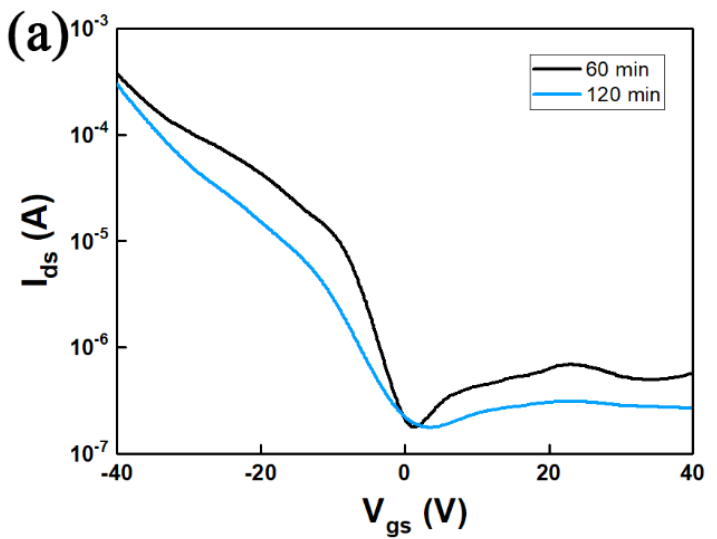

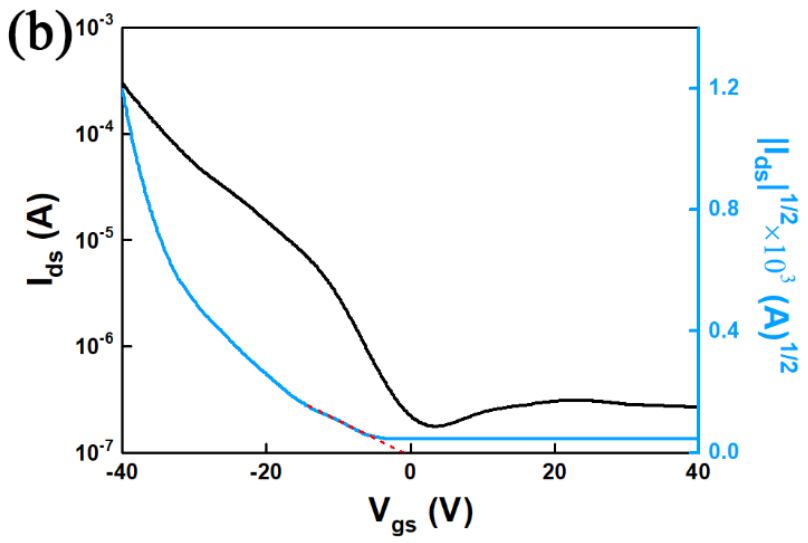

2 Figure S8. (a) Comparison of transfer characteristics of the Ni-MOF-FET reacting for

$360 \mathrm{~min}$ with the one for $120 \mathrm{~min}$. (b) Left: actual current ( $\left.\mathrm{Ids}_{\mathrm{ds}}\right)$ versus gate voltage $\left(\mathrm{V}_{\mathrm{gs}}\right)$,

4 right: square root of current $\left(\mathrm{Ids}^{1 / 2}\right)$ versus gate voltage $\left(\mathrm{V}_{\mathrm{gs}}\right)$. The threshold voltages and

5 subthreshold swings were $-10 \mathrm{~V}$ and $1.4 \mathrm{~V} /$ decade (reaction time of $120 \mathrm{~min}$ ).

7

8

\section{Reference}

(1) Kamiya, T.; Nomura, K., Hosono, H. Present Status of Amorphous In-Ga-Zn-O

Thin-Film Transistors. Sci. Technol. Adv. Mater. 2010, 11, 1-5.

(2) Sarkar, D.; Banerjee, K. Proposal for Tunnel-Field-Effect-Transistor as Ultra-

Sensitive and Label-Free Biosensors. Appl. Phys. Lett. 2012, 100, 1-4. 